\title{
Researching market and supply-chain opportunities for local foods systems: Setting priorities and identifying linkages
}

\author{
Dawn Thilmany, a,* David Conner, ${ }^{\mathrm{b}}$ Kynda Curtis, ${ }^{\mathrm{c}}$ Kathleen Liang, ${ }^{\mathrm{d}}$ Kranti Mulik, ${ }^{\mathrm{e}}$ \\ Jeffrey O’Hara, ${ }^{\mathrm{e}}$ Martha Sullins, ${ }^{\mathrm{f}}$ and Tim Woods ${ }^{\mathrm{g}}$
}

Submitted June 12, 2013 / Revised August 26, 2013 / Published online August 29, 2013

Citation: Thilmany, D., Conner, D., Curtis, K., Liang, K., Mulik, K., O’Hara, J., Sullins, M., \& Woods, T. (2013). Researching market and supply-chain opportunities for local foods systems: Setting priorities and identifying linkages. Journal of Agriculture, Food Systems, and Community Development, 3(4), 131-137. http://dx.doi.org/10.5304/jafscd.2013.034.018

Copyright (C) 2013 by New Leaf Associates, Inc.

\begin{abstract}
There is an increasing array of land-grant, nonprofit, and other academic programs intended to support the development of food system enterprises and programs. However, research to track

\footnotetext{
a, * Corresponding author: Dawn Thilmany, Professor and Agribusiness Extension Economist, Department of Agriculture and Resource Economics, B325 Clark, Colorado State University, Fort Collins, Colorado 80523-1172 USA; +1-970-491-7220; Dawn.Thilmany@ColoState.edu

b David Conner, Assistant Professor, Department of Community Development and Applied Economics, University of Vermont, 205H Morrill Hall, 146 University Place, Burlington, Vermont 05405 USA; david.conner@uvm.edu Applied Economics, Utah State University, 4835 Old Main Hill, Logan, Utah 84322-4835 USA; kynda.curtis@usu.edu

d Chyi-lyi (Kathleen) Liang, Professor, University of Vermont, Department of Community Development and Applied Economics, 103 C Morrill Hall, Burlington, Vermont 05405 USA; cliang@uvm.edu
}

c Kynda R. Curtis, Associate Professor, Department of
\end{abstract}

consumers' evolving preferences and behaviors within these systems and to measure the intended policy outcomes of any public investments in these systems is lagging. This research commentary represents a compilation of opinions and insights from those who are interested in exploring research priorities for economic, marketing, and supply-chain aspects of local food systems. The priorities that emerge are framed in the following way: (1) opportunities for increased and more targeted research to help identify gaps in the

\footnotetext{
e Kranti Mulik and Jeffrey K. O'Hara, Senior and Agricultural Economists, Union of Concerned Scientists, $1825 \mathrm{~K}$ Street, NW, Suite 800, Washington, D.C. 20006 USA; +1-202-3316944, kmulik@ucsusa.org and johara@ucsusa.org

f Martha Sullins, Extension Regional Specialist, Colorado State University Extension, 1525 Blue Spruce Drive, Fort Collins, Colorado 80524-2004 USA; Martha.Sullins@,colostate.edu

g Tim Woods, Department of Agricultural Economics, 402 CE Barnhart, University of Kentucky, Lexington, Kentucky 40546 USA; tim.woods@uky.edu
} 
literature; (2) areas where current localized research projects could be leveraged and scaled up to the national level; and (3) innovative projects and partnerships that are evolving to bridge both knowledge and systems gaps.

\section{Keywords}

community impacts, local foods, market access, market development, supply chains

\section{Introduction}

The interest in local food systems appears to stem in part from the public's perception that localization activities will address several key food marketing and supply-chain issues, such as improving market access for small and midsized farms, demonstrating less capital-intensive yet financially sustainable start-up models for beginning farmers and ranchers, and supporting broader communitybased economic development strategies (Martinez et al., 2010; Onozaka, Nurse, \& Thilmany McFadden, 2011). Another key driver may be the U.S. Department of Agriculture's Know Your Farmer, Know Your Food initiative, one of the most visible new public initiatives that has required USDA agencies to consider cross-department investments to better connect the public to their food sources.

Subsequently, there is an increasing array of land grant, nonprofit, and other academic programs intended to support the development of food system enterprises and programs. However, research to track consumers' evolving preferences, behaviors, and motivations for new market innovations, and to measure intended policy outcomes of public investments in food systems, should develop alongside private- and public-sector decisions about how to support such innovations. This article represents a compilation of opinions and insights from those who are interested in exploring research priorities for economic, marketing, and supply-chain aspects of local food systems. To compile these ideas into a set of priorities, responses were framed in the following way: (1) opportunities for increased and more targeted research to help identify gaps in the literature; (2) areas where current localized research projects could be leveraged and scaled up to the national level; and (3) innovative projects and partnerships that are evolving to bridge both knowledge and systems gaps. Although the particular focus of this paper is on the marketing and supply-chain issues at play in the local food system, we realize that these represent only a small share of the larger set of issues that must be considered.

\section{Identifying Opportunities for Applied Research and Outreach}

The primary focus of this commentary is to identify opportunities for applied research. However, given the nature of this team, which includes many with Cooperative Extension or other outreachoriented academic positions, we will integrate a discussion of outreach needs as well. In subsequent sections, therefore, we will discuss how outreach programming that has resulted in various grassroots, pilot, and localized projects could be leveraged to address the opportunities identified here.

Perhaps the most essential challenge for this field of study is to clearly identify what the food system represents with respect to the actors and organizations involved in its design, planning, and implementation. Important criteria include the geographic boundaries, food system components (production, supply chain, consumers, natural resources, and input-oriented agribusinesses), and issues of interest (economics, public health, environment, social networks, self-sufficiency). Given the multifaceted nature of food in our society, clarification of the scope is essential to research design, yet no clear standards have emerged. Therefore, applied research in this area might seek to examine and formulate integrated approaches that clarify these interpretations and definitions. Although identifying and defining a food system and its components will always be place-based, applying best practices from a body of literature may help to make that process more effective.

Once the food system is better defined, it is important to explore and understand the behavior of various actors and stakeholders. This field has already started to extend and modify existing economic theories to introduce more consumerbehavior factors into modeling consumers' decisions. However, there is still much to be learned in order to understand how messaging, technology, 
market structure, and various policies influence consumers' choices in acquiring healthy food, local food, or any specific type of value-added products that may emerge from localized food systems. Some of this research will continue to focus on how differences in demographics (for example, the role of income, the influences of ethnicity, or youth behaviors) influence consumer choices, but there are also growing opportunities to consider the role of certain food-system stakeholders, such as schools, restaurants, community gardens, and food banks, in how consumers make choices about local food production and products.

Along these lines, there is also interest in exploring if and how web-based infrastructure can be better used to guide consumers in making healthy and affordable choices. More broadly, we could explore an array of societal factors - access, information, and social networks - that lead consumers to make decisions and take actions in their food systems, which would contribute to the broader consumer behavior literature.

As this discussion of consumer influences and behavior suggests, agricultural economists and marketing analysts should be motivated and encouraged to frame integrated and multidisciplinary collaborations. Beyond consumer behavior (where psychologists, sociologists, and educational professionals may be valuable partners), there are many opportunities to work with supply-chain and industrial-organization academics and practitioners to explore unique aspects of local food distribution and market development and growth.

Numerous innovative business models are emerging to address supply challenges that have traditionally limited local products to local markets concepts. A current study on community supported agriculture (CSAs) (Woods \& Ernst, 2013) is uncovering some of these trends in that food distribution model, which complements existing work on farmers' markets and food hubs (much of which is summarized on the USDA Agricultural Marketing Service website (2013) and in Martinez et al. (2010).

In a broader sense, there is a need to better understand the institutions that are providing market access and opportunities to more localized marketing systems. Research could effectively contribute to policy and business discussions if it is designed to examine the capacity, governance, policy, and resource limitations of organizational management for various categories of food system participants. This includes private-sector enterprises and the growing number of nonprofit and educational institutions and government agencies that recognize that these markets may perform differently than traditional food supply chains. This would complement the broader industrial-organization literature that already addresses agricultural and food markets. Many agree that localized systems have an added dimension of complexity due to (1) the diversity of players involved, and (2) the fact that the businesses and organizations they manage may have missions that do not prioritize profits and efficiency, but must still operate in a financially sustainably manner.

The supply challenges faced are often based on missing or undercapitalized institutions, but also relate to the fragmented set of food producers who participate in such markets. There is a growing set of studies that identify and examine differences among producers (and the supply-chain decisionmakers to whom they sell) by type of operations both within and across marketing channels. Learning more about discrete types of producers will allow for improved and more targeted technical assistance and policy support that address how different system participants make production, distribution, pricing, and organizational decisions.

One particularly relevant example is the role of local markets, and the motivations of consumers who buy from these markets, to provide market access to small farms and beginning farmers. For example, state-based research finds that the success of small farms may be enhanced by the expansion of direct market outlets, access to and use of smaller, fragmented lands, production of highvalue crops, as well as multiple-enterprise or diversified activities such as agritourism (Hardesty \& Leff, 2010; Watson \& Thilmany, 2008). This counters reports that there is a lack of profitability or sustainability among small farms due to limited access to financial capital, land, and affordable health care (National Young Farmers' Coalition, 2011). Therefore, perhaps the "exceptional" cases of what is working should be highlighted to reveal 
the variety of options available to small (or beginning) farms.

Although farm profitability and "love of farming" have been used as measures of success in the literature (Muhammad, Tegegne, \& Ekanem, 2004), there may be more appropriate measures for this nontraditional farming sector. A comprehensive investigation should be conducted of the business owner (such as background, education, experience, personality, etc.), financial performance, farming operation, market opportunities, and influencing governmental regulations. Thilmany McFadden and Sureshwaran (2011) noted that the customerfocused marketing channels that some small and beginning farmers choose to operate within often require a modified approach to production planning. Still, new farmers enter agriculture only to find that there are few technical assistance offerings or, for that matter, limited or nonexistent management and decision tools oriented toward production and marketing planning for their smaller-scale, diversified operations. Research focused on best practices, benchmark production and financial numbers, and characteristics of successful operations would all help to fill this void.

\section{Best Practices Identified from Local Communities of Practice That Could Be Scaled To the National Level}

The previous section identified many gaps in the research on local food systems. However, it is important to highlight research from more localized efforts that could better inform the literature if it were replicated, broadened to a larger geography, and updated to incorporate current market dynamics. For example, there are many significant opportunities for regional collaboration especially collecting longitudinal price, volume, and availability data from vendors and consumers associated with farm markets, on-farm retailing, CSAs, local food retailers, schools, food consumer co-ops, and regional food hubs. This would complement and augment the market information that has benefitted more traditional food supply chains for years (through the USDA's Agricultural Marketing Service programs), and allow for better research on the place-based aspects of local food markets, while allowing each place to compare its market situation to other areas of the country or to different food system enterprises. Beyond research, price information allows for more effective risk management strategies, particularly crop insurance program development, for this class of farmers.

There is a growing number of county, city, state, watershed, and regional food system assessments that seek to more closely align local food production with residents' ability and intention to purchase foods in an identified region. This process is often challenging. For example, researchers and Cooperative Extension professionals working alongside key supporters of an emerging local food system are often asked to work with a nonlocal "expert" who flies in with his or her own research agenda, engages the local clients, and then completes the research without ever fully understanding the local context. Although more expertise is always welcome, this process is problematic if the expert maintains no long-term presence, and instead leaves local professionals to do follow-up process work and educational programming. Although this pattern may have emerged because land grant institutions, Departments of Agriculture, and other agricultural entities were slow to assist local communities in better understanding their food system needs, there is concern about nonagricultural or supply-chain researchers jumping into the field with little understanding of the culture of agriculture and food production. The diverse research approaches, process, and impact of these assessments have illustrated the importance of developing more standardized approaches which can be adapted and refined to more placebased situations and programs.

In the context of local food assessments, one key theme emerges that relates matching local production with consumption and, where public health stakeholders are involved, possibly examining how food availability also interfaces with recommended dietary standards. This type of analysis could be framed at the national level as well. While it is intuitively obvious that the U.S. agricultural landscape isn't growing the mix of crops needed to support recommended levels of fruit and vegetable consumption, estimating the acreage implications of any production changes is challenging. There are perhaps an infinite number 
of crop acreage combinations that could achieve more localized production, but many variables influence the resulting estimates. Some studies (Buzby, Wells, \& Vocke, 2006; Ribera, Yue, \& Holcomb, 2012; Young \& Kantor, 1999) have estimated changes in U.S. crop acreage that healthier consumption would generate by assuming that fruit and vegetable acreage would increase in proportion to the corresponding increase in consumption.

A forthcoming report by the Union of Concerned Scientists uses a computable general equilibrium model developed by the Global Trade Analysis Project (GTAP) to estimate changes in acreage. GTAP accounts for how changes in relative market prices affect the consumption of all goods, the international implications of changing trade flows, and the substitutability of farmland relative to other inputs when production expands. Conducting research on an issue this complex at the national level is a substantial challenge and will require continual refinement from local and state efforts to assure that the model characterizes the changing production and supply-chain dynamics that would come with new cropping patterns if they were to become policy goals.

In the context of considering dietary recommendations when examining local food systems, there seem to be parallel multistate efforts stirring in the consumer sciences and nutrition community. Although those projects have a somewhat different focus than those of agricultural economists, it is clearly an opportunity for better multidisciplinary integration around research on consumer behavior and choices.

\section{Innovative Approaches for "Bridging The Research Gap" on Local Food Systems}

To better understand the institutions, market linkages, and behavior of participants within food systems, researchers need to develop a vetted body of knowledge and practice that will support emerging food systems. This involves developing and leveraging partnerships that facilitate data collection and sharing, often in less conventional study settings and using innovative research methods. Although there is a growing set of literature on market behavior and performance in local food systems, most researchers working in this area agree there is still progress to be made in understanding consumer-driven markets, including applied research on how and if localization efforts are contributing to the multiple values and outcomes that the public wants to derive from these initiatives.

Two approaches in this area are emerging: (1) a focus on research developed through case studies that assess relationships along an entire supply chain; and (2) investigating key, and possibly new, topics identified as critical to successful food systems development. The transfer of knowledge from a local food system level to a regional or national level is most likely to be applicable and scalable if based on observed conditions and relationships. As a starting point, the University of California, Davis has compiled an extensive bibliography on community food systems based on peerreviewed literature from 2000 through January 2013 (Campbell, Feenstra, Galt, \& Marshall, 2013). Currently, however, much of the work documenting contextual studies is difficult to locate and build upon, as it often appears in less recognized literature and instead is posted on the Web to share with local organizations and state extension sites. (Many refereed journals shy away from publishing studies on highly localized research settings.)

One key topic is the role of food hubs. A team of researchers examined how successful valuesbased distribution networks involving small- and medium-scale producers were affected by access to financial capital, governmental regulations and policies, and entrepreneurial characteristics, using in-depth case studies of western U.S. food distribution networks and interviews with funders, industry associations, government agencies, and economic and community development professionals. This study required examining diverse qualitative data (Feenstra, Hardesty, Visher, Thilmany, Gillpatrick, Dyer, \& Edge, 2010).

Food hubs also represent one area of study where the production, processing, distribution, and business-development functions that support food systems are centrally linked to directly connect producers with consumers and to expand growth opportunities for local businesses. In short, whether they are primarily Web-based or have a 
physical site, they facilitate localization. Case-study research on food hubs may provide information on how alternative supply chains work most effectively, given different scales of producers, market potential, supply-chain logistics, and stakeholder goals and objectives (Diamond \& Barham, 2012; Matson, Sullins, \& Cook, 2013).

In order to justify future investments in food hubs as well as the broader set of food system innovations and capacity-building, the public and private values attributable to food systems participants and innovations will need to be better described and quantified. These include investments and technical assistance related to: (1) human capital (land grant faculty, farmers, business and community development specialists); (2) organizational supports, such as Land Link, ${ }^{1}$ MarketReady, ${ }^{2}$ and farm-transition programs, as well as lending to new agricultural business models; and (3) the physical infrastructure (or partnerships with those already managing existing infrastructure) needed to support new food systems models. As one example, brick and mortar investments are typically eligible to benefit from USDA Rural Development grants targeted at low-population areas. However, research may reveal that investments in more highly populated areas could create service centers that would shorten supply chains (and reduce costs) by moving processing and distribution closer to population centers while still benefitting producers from rural areas.

This article was intended to give a very broad overview of the priorities that applied researchers and outreach specialists offer up to those who want to see success in the marketing, supply-chain, and consumer-oriented innovations emerging in local and regional food systems. As this sector moves from the high-growth, experimental phase to an era of maturing organizations and projects, evaluation and assessment of what does and does not work will be very important.

\footnotetext{
${ }^{1}$ See more about the Land Link program at http://www.cfra.org/landlink

${ }^{2}$ See more about MarketReady at http://www.uky.edu/ $\underline{\text { fsic/marketready }}$
}

\section{Acknowledgements}

The authors wish to acknowledge a number of USDA NIFA Grants, collaborations with USDA Economic Research Service and Agricultural Marketing Service colleagues for projects and discussions that informed this commentary and funding support from each of their state Agricultural Experiment Stations and Extension programs.

\section{References}

Buzby, J. C., Wells, H. F., \& Vocke, G. (2006). Possible implications for U.S agriculture from adoption of select dietary guidelines (Economic Research Report No. 31). Washington, D.C.: U.S. Department of Agriculture. Retrieved from http://www.ers.usda.gov/ publications/erreconomic-research-report/ err31.aspx\#. UhaM5n Qjgs

Campbell, D., Feenstra, G., Galt, R., \& Marshall, C. (2013). Community food systems bibliography - March 2013 updates. University of California, Davis. Retrieved from http://www.sarep.ucdavis.edu/ sfs/CFS Bibliography Updated 2013.pdf

Diamond, A., \& Barham, J. (2012). Moving food along the value chain: Innovations in regional food distribution. Washington, D.C.: Marketing Services Division, Agricultural Marketing Service, USDA. http://dx.doi.org/10.9752/MS045.03-2012

Feenstra, G., Hardesty, S., Visher, D., Thilmany, D., Gillpatrick, T., Dyer, J., \& Edge, J. (2010). Valuesbased distribution networks to enhance the prosperity of small- and medium-sized producers [Research Update]. Journal of Food Distribution Research.

Hardesty, S. D., \& Leff, P. (2010). Determining marketing costs and returns in alternative marketing channels. Renewable Agriculture and Food Systems, 25(1), 24-34. http://dx.doi.org/10.1017/S1742170509990196 Martinez, S., Hand, M. S., Da Pra, M., Pollack, S., Ralston, K., Smith, T., ... Newman, C. (2010). Local food systems: Concepts, impacts, and issues (Economic Research Report No. 97). Washington, D.C.: U.S. Department of Agriculture, Economic Research Service. Retrieved from http://www.ers.usda.gov/ publications/err-economic-research-report/err97. aspx\#.Uha4in Qjgs 
Matson, J., Sullins, M., \& Cook, C. (2013). The role of food hubs in local food marketing (USDA Rural Development Service Report No. 73). Washington, D.C.: USDA. Retrieved from http://www.rurdev. usda.gov/SupportDocuments/USDAReportFoodh ub2013.pdf

Muhammad, S., Tegegne, F., \& Ekanem, E. (2004). Factors contributing to success of small farm operations in Tennessee. Journal of Extension, 42(4), 4RIB7. Retrieved from http://www.joe.org

National Young Farmers' Coalition. (2011). Building a future with farmers: Challenges faced by young, American farmers and a national strategy to help them succeed. New York: Author. Available at: http://www.youngfarmers.org/reports/Building_A Future With Farmers.pdf

Onozaka, Y., Nurse, G., \& Thilmany McFadden, D. (2011). Defining sustainable food market segments: Do motivations and values vary by shopping locale? American Journal of Agricultural Economics, 93(2), 583589. http://dx.doi.org/10.1093/ajae/aaq152

Ribera, L. A., Yue, C., \& Holcomb, R. B. (2012). Geographic impacts on U.S. agriculture of the 2010 dietary nutrition guidelines. Choices: The Magazine of Food, Farm, and Resource Issues, 27(1). http://purl.umn.edu/122796
Thilmany McFadden, D. \& Sureshwaran, S. (2011). Theme overview: Innovations to support beginning farmers and ranchers. Choices: The Magazine of Food, Farm and Resource Issues, 26(2). Retrieved from http://www.choicesmagazine.org

USDA Agricultural Marketing Service. (2013). Farmers markets and local food marketing. Retrieved from http://www.ams.usda.gov/AMSv1.0/

Watson, P., \& Thilmany, D. (2008). Regional agriculture as a national industry. In S. C. Blank (Ed.), The economics of American agriculture: Evolution and global development (pp. 349-378). Armonk, New York: M. E. Sharpe.

Woods, T., \& Ernst, M. (2013, August). National survey of CSAs: Emerging marketing and business strategies. Presentation at Innovative Strategies in Direct to Consumer Marketing Symposium, USDA Agricultural Marketing Service, Washington, D.C. Young, C. E., \& Kantor, L. S. (1999). Moving toward the food guide pyramid: Implications for U.S. agriculture (USDA Agricultural Economic Report No. 779). Washington, D.C.: U.S. Department of Agriculture. 